\title{
PROJEKAT ARMIRANOBETONSKE VIŠESPRATNE ZGRADE U NOVOM SADU PREMA EVROKODOVIMA
}

\section{THE PROJECT OF MULTI-STOREY REINFORCED CONCRETE BUILDING IN NOVI SAD ACCORDING TO EUROPEAN STANDARDS}

\author{
Igor Lazarević, Fakultet tehničkih nauka, Novi Sad
}

\section{Oblast - GRAĐEVINARSTVO}

Kratak sadržaj - U prvom delu rada prikazan je projekat armiranobetonske višespratne zgrade $\mathrm{Po}+\mathrm{Pr}+5$ a u drugom delu je analiziran uticaj torzionih efekata na seizmički odgovor konstrukcije prema evropskim standardima.

Ključne reči: Armiranobetonska zgrada, Evropski standardi, Uticaj torzionih efekata

\begin{abstract}
The first part of the work consist the project of multi-strorey reinforced concrete building, basement + ground floor + 4 stories, and the second part consist analysis of the impact of torsion effects on the seismic response of building structures.
\end{abstract}

Keywords: Reinforced concrete building, European standards, Impact of torsion effects

\section{UVOD}

Projektnim zadatkom predviđeno je projektovanje armiranobetonske višespratne zgrade $\mathrm{Po}+\mathrm{Pr}+5$, skeletnog tipa sa platnima za ukrućenje, prema evropskim standardima na osnovu zadatog arhitektonskog plana. Lokacija objekta je Novi Sad.

\section{OPIS PROJEKTA}

\subsection{Projektni zadatak i arhitektonsko rešenje}

Projektnim zadatkom predviđeno je projektovanje stambeno poslovne zgrade u Novom Sadu, spratnosti podrum + prizemlje +5 spratova $(\mathrm{Po}+\mathrm{Pr}+5) . \mathrm{U}$ podrumu $\mathrm{i}$ prizemlju se nalazi poslovni prostor (lokali).Na ostalim spratovima se nalaze stanovi. Lokali su površine od $45 \mathrm{~m} 2$ do $120 \mathrm{~m} 2$, dok su stanovi površine od $29 \mathrm{~m} 2$ do $70 \mathrm{~m} 2$. Struktura stanova je ista po svakom spratu, a u okviru svakog stana se nalazi lođa. U prizemlju se nalazi i prolaz za vozila, koji vodi do parkinga i garaže.

\subsection{Konstruktivni sistem zgrade}

Konstruktivni sistem objekta je ukrućeni, armiranobetonski, skelet, sa pločama oslonjenim na grede dva upravna pravca, koje preuzimaju opterecenje od ploče, prenose dalje do stubova, a stubovi prenose do temeljne ploče, koja opterećenje prenosi na tlo.

\section{NAPOMENA:}

Ovaj rad proistekao je iz master rada čiji mentor je bio dr Đorđe Lađinović, red. prof.
Objekat je ukrućen sa po dva zidna platna $u$ dva ortogonalna pravca, čija je uloga da prime horizontalne sile, nastale od seizmike i prenesu ih do temelja, da smanje horizontalna pomeranja, povecaju celokupnu krutost objekta, smanje periode oscilovanja. Temeljna konstrukcija je prvobitno predviđena kao temeljna ploča, ali zbog problema sa probijanjem, ploča je ojačana gredama dva upravna pravca.

Vertikalna komunikacija je odvojena za poslovni i stambeni deo objekta, a vrsi se liftom i dvokrakim stepeništem.

Stubovi zajedno sa gredama čine višebrodne ramove, koji se pružaju u dva ortogonalna pravca. U x-pravcu postoji osam ramova, a u y-pravcu pet ramova na različitim rastojanjima. Ose u horizontalnom pravcu su označene sa brojevima od 1 do 5 , a u vertikalnom pravcu sa slovima od A do H. U osnovi, objekat je u obliku ćiriličnog slova „Г,, dimenzija $31.2 \mathrm{~m}$ x $22.8 \mathrm{~m}$, površine $570 \mathrm{~m} 2$. Spratna visina podruma i prizemlja je $3.96 \mathrm{~m}$, a ostalih spratova $3.24 \mathrm{~m}$. Ukupna visina objekta je $27.42 \mathrm{~m}$.

\subsection{Analiza opterećenja}

Konstrukcije armiranobetonskih višespratnih zgrada je neophodno projektovati tako da mogu da prihvate i temeljima prenesu uticaje od svih relevantnih opterećenja i njihovih kombinacija. Za zadatu armiranobetonsku konstrukciju stambene zgrade definisane su sledeće vrste opterećenja:

- $\quad$ stalno opterećenje

- korisno opterećenje

- $\quad$ opterećenje od snega

- opterećenje od vetra

- $\quad$ seizmičko opterećenje

Stalna opterećenja su ona koja potiču od sopstvene težine konstruktivnih elemenata i nekonstruktivnih delova zgrade. Korisno opterećenje definisano je standardom Evrokod 1 EN 1991-1-1:2002 [1], na osnovu kategorije upotrebe prostorija u stambenim zgradama. Opterećenje snegom se računa prema evropskim standardima EN 1991-1-3:2003 [1] za krovne nagibe između $0^{\circ}$ i 30 $\mathrm{i}$ aplicira se na konstrukciju u vidu jednakopodeljenog površinskog opterećenja. Opterećenje vetrom računa se prema evrokod standardu EN 1991-1-4:2005 [1] i nanosi se na konstrukciju kao površinsko opterećenje, nakon čega se konvertuje u linijsko optereće nje. Za seizmiško opterećenje je izabrana metoda ekvivalentnih bočnih sila 
koja nije implementirana u softverskom paketu Tower poput multimodalne analize. Opterećenje je proračunato za svaku etažu i zatim uneto u program kao druga opterećenja statičkog karaktera.

- Objekat se nalazi na tlu kategorije B

- Odnos a/a jednak je 0,2

- Koeficijent prigušenja jednak je 0,05

\subsection{Modeliranje konstrukcije}

Konstrukcija je modelirana u programskom softveru Tower 6, koji je baziran na metodi konačnih elemenata. Svi uticaji u konstrukciji određeni su na osnovu proračunskog modela koji dovoljno realno predstavlja stvarnu konstrukciju i njeno ponašanje pod dejstvom opterećenja. Ovim paketom omogućeno je prostorno modeliranje konstrukcije površinskim i linijskim elementima. Međuspratne tavanice, temeljna i krovna ploča, kao i armirano betonska zidna platna su modelirana kao površinski elementi, dok su grede i stubovi modelirani kao linijski elementi. Svi elementi su modelirani tako da njihove geometrijske i mehaničke karakteristike odgovaraju zadatim projektom. Mehaničke karakteristike, kao što su računska čvrstoća betona na pritisak, modul elastičnosti, Poasonov koeficijent i koeficijent temperaturnog šrenja određeni su markom betona. Geometrijske karakteristike su pridružene elementima usvajajući bruto betonske preseke, zanemarujući doprinos armature.

Međuspratne tavanice- Ploče predstavljaju elemente koji su dominantno opterećeni na savijanje, koje deluje normalno na srednju ravan ploče. Usled deformisanja ploče pod dejstvom opterećenja, u njoj se javljaju presečne sile: momenti savijanja (M), momenti torzije (Mt), i transverzalne sile (T). Realno, u ploči se javljaju i aksijalne sile usled opterećenja u srednjoj ravni ploče, ali je prilikom proračuna smatrano da će veći deo tog opterećenja da preuzmu zidovi. Sve ploče su tretirane kao tanke, jer im je odnos debljine i kraćeg raspona manji od $0.2(\mathrm{~d} / \mathrm{L}=15 / 540=0.03)$. Minimalna debljina ploče je min $\mathrm{d}=4 / 5 \times 5.4=4.32$, odnosno $7 \mathrm{~cm}$ za ploče opterećene jednakopodeljenim opterećenjem, odnosno $10 \mathrm{~cm}$ ako je reč o pločama po kojima se kreću putnička vozila, po propisima koje daje Pravilnik BAB. Ploče se tretiraju kao slobodno oslonjene na gredne nosače, međutim u realnosti je ta veza ipak elastično uklještenje (veličina uklještenja zavisi od krutosti same grede), ali ovakvim posmatranjem ostajemo na strani sigurnosti, jer se dobijaju veći momenti $\mathrm{u}$ polju. Ipak, povijanjem pojedinih šipki armature $u$ gornjem polju, iznad oslonaca, prihvataju se eventualni negativni momenti koji se tu mogu javiti. Ploča se dimenzioniše prema momentima savijanja $u$ dva ortogonalna pravca, dok se momenti torzije zanemaruju.

Zidni nosači- Površinski nosači su dominantno opterećeni u svojoj ravni, što izaziva normalne i smičuće napone. Pri prijemu horizontalnog opterećenja imaju najveći značaj zbog neuporedivo veće krutosti u poređenju sa stubovima.

Zidna platna- Zbog svoje mnogo veće savojne krutosti u odnosu na stubove, oni će prihvatati najveći deo horizontalnog opterećenja. Njihova uloga je da prime seizmičke sile, ali i eventualne momente torzije koji se mogu pojaviti (usled pojave prslina svakako dolazi do promene krutosti elemenata, pa je i poklapanje centra mase i centra krutosti praktično nemoguće, pa će neminovno doći do pojave torziranja zgrade u osnovi). Iz funkcionalnih razloga, deo zidova za ukrućenje postavljen je oko stepeništa. Aksijalno opterećenje povoljno utiče na rad ovih zidova. Modelirani su kao površinski elementi debljine $\mathrm{d}=20 \mathrm{~cm}$.

Stepenišni kraci -modelirani su kao kosi površinski elementi, oslonjeni na gredu na jednoj strani i uklješteni u zidno platno na drugoj strani. Međupodesti su modelirani kao ravni površinski elementi uklješteni u zidno platno.

Stubovi-Primaju i prenose gravitaciono opterećenje do temelja. Dominantno su opterećeni na pritisak, ali zbog činjenice da u ramovskom sistemu stubovi rade zajedno sa gredama, isti će biti opterećeni i momentom savijanja, i to $\mathrm{u}$ dva pravca, čime postaju dvoosno savijani. U ukrućenom skeletnom sistemu, kao što je i ovaj, veliki deo horizontalnog opterećenja primaju zidovi za ukrućenje, zbog neuporedivo veće krutosti, ali se ne sme zanemariti doprinos stubova pri prijemu ovog opterećenja. Međutim, stubovima, kao elementima dominantno opterećenim na pritisak, nije redukovana torziona krutost pri modeliranju. Zbog alternativnog dejstva horizontalnih sila, usvojeno je simetrično armiranje stubova.

Grede-Prilikom zadavanja poprečnih preseka, gredama je smanjena torziona krutost 10 puta, zbog primene linearne teorije elastičnosti i neminovne preraspodele uticaja, kao posledice realnih karakteristika ponašanja materijala $\mathrm{i}$ elemenata. Pri graničnom stanju nosivosti, već nakon pojave prvih prslina, krutost greda se značajno redukuje.

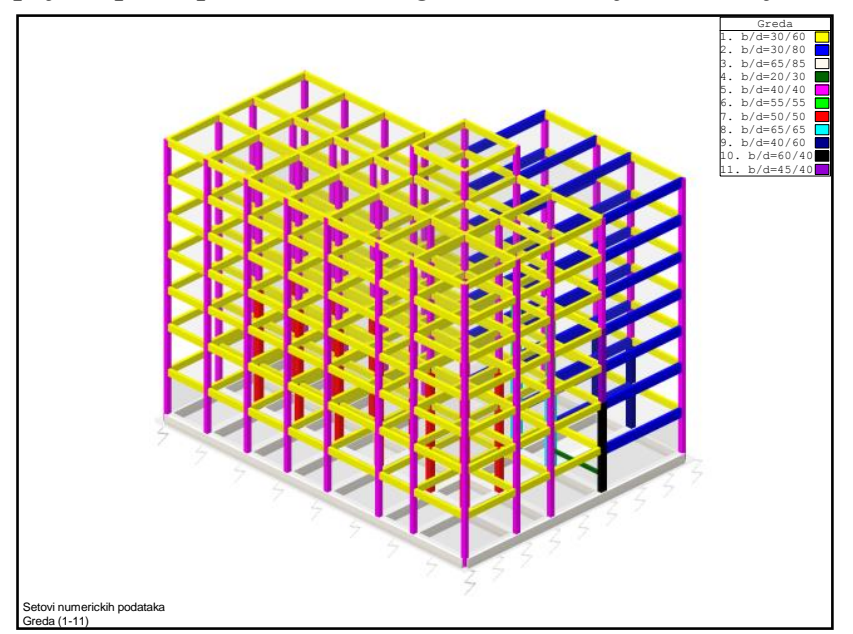

Slika 1. 3D model konstrukcije

Uticaj tla na konstrukciju je modeliran kao Vinklerova podloga. Vinklerov model je jednoparametarski model tla kojim se tlo tretira kao elastična podloga, a zasniva se na proporcionalnosti između pritiska i sleganja. Ovim modelom tlo je zamenjeno beskonačnom serijom elastičnih, međusobno nezavisnih opruga. Krutost opruge predstavlja proizvod koeficijenta podloge i pripadajuće površine opruge. Osnovni nedostaci ovog modela su to što pritisak u nekoj tački nije funkcija sleganja samo te tačke, a tlo se ne sleže samo ispod temelja, nego i izvan njega. Takođe, u kontaktnoj površini nije moguće preneti napone zatezanja, što ovaj model omogućava. Koeficijent podloge je uzet kao konstanta tla, međutim on realno zavisi i od oblika i veličine kontaktne površine bloka kojim se određuje. Ipak, primenom Vinklerovog modela 
omogućeno je obuhvatanje interakcije temelj-tlo. Primena višeparametarskih modela je mnogo komplikovanija, a takođe predstavlja samo grubu aproksimaciju realnog ponašanja tla, tako da Vinklerov model predstavlja optimalno rešenje po pitanju tačnosti rezultata proračuna i jednostavnosti primene modela.

\subsection{Dimenzionisanje i armiranje elemenata}

U softverskom paketu Tower 6 izvršeno je dimenzionisanje odabranih ploča: temeljne ploče, ploče prizemlja i ploče tipskog sprata. Ploče prenose opterećenje $u$ dva pravca, te su $s$ toga armirane proračunskom armaturom u dva pravca i vođeno je računa o pravilima za armiranje. Projektnim zadatkom predviđeno je da se dimenzioniše po jedan ram $u$ oba pravca, i to ram u osi A i ram u osi 3. Dimenzionisanje i armiranje je izvršeno saglasno evropskom pravilniku, prema uticajima merodavnih graničnih kombinacija. Za sve elemente konstrukcije predviđena je marka betona C30/37, dok su svi elementi armirani rebrastom armaturom B500.

\subsection{Dimenzionisanje i armiranje elemenata}

Prema evropskom pravilniku neophodno je bilo uraditi sledeće kontrole konstrukcije:

- Kontrola napona u stubovima

- Kontrola napona u zidovima

- Ograničenje relativnog spratnog pomeranja

- Kontrola napona u tlu

Nakon analize zaključeno je da konstrukcija zadovoljava uslove svih prethodno nabrojanih kontrola.

\section{UTICAJ POLOŽAJA ZIDOVA ZA UKRUĆENJE NA ODGOVOR KONSTRUKCIJE SAGLASNO EC8}

\subsection{Uvod}

Prema EC8 pored otpornosti i krutosti konstrukcije u dva pravca zahteva se torziona otpornost i krutost konstrukcije. Horizontalno seizmičko kretanje je fenomen u dva pravca, pa konstrukcija zgrade mora da bude sposobna da se odupre horizontalnim dejstvima u bilo kom pravcu. Da bi zadovoljili ovaj zahtev raspoređujemo noseće elemente u osnovi međusobno ortogonalno, obezbeđujući slične karakteristike otpornosti i krutosti u oba glavna pravca. Izbor karakteristika krutosti konstrukcije treba da ograniči nastanak prekomernih pomeranja, koja mogu da dovedu do nestabilnosti usled efekata drugog reda ili do prevelikih oštećenja.

Osim bočne (fleksione) otpornosti i krutosti, konstrukcije zgrada treba da poseduju i adekvatnu torzionu otpornost $\mathrm{i}$ krutost sa ciljem da se smanji nastajanje torzionih pomeranja usled kojih dolazi do neravnomernog naprezanja, različitih konstrukcijskih elemenata. $U$ tom smislu su u jasnoj prednosti konfiguracije u kojima su glavni noseći elementi, koji se suprotstavljaju seizmičkim dejstvima, raspoređeni bliže obimu zgrade.

Zašto je bitno obezbediti takav oblik osnove zgrade i raspored konstrukcijskih elemenata? Odgovor na ovo pitanje je da upravo pravilnim izborom dispozicije konstrukcije a ujedno i pravilnim rasporedom konstrukcijskih elemenata sprečavamo pojavu velikog ekscentriciteta centra mase i centra krutosti, što za posledicu usled dejstva seizmičkih sila ima pojavu velikog momenta torzije koji deluje na našu konstrukciju, što dalje povlači za sobom kao posledicu velika pomeranja i uticaje, naročito $u$ obodnim elementima konstrukcije (nepravilna dispozicija $\rightarrow$ veliki ekscentricitet $\rightarrow$ veliki momenat torzije $\rightarrow$ velika pomeranja i uticaji).

Kod izbora zgrade u osnovi prednost je uvek na strani sažetih i simetričnih osnova. Dugačke, razuđene, nesimetrične i nepravilne osnove treba izbegavati. Simetrija u osnovi zgrade je mera u pravcu postizanja jednostavnosti konstrukcije, ali i mera kojom se primarno doprinosi postizanju translatornog pomeranja tavanica (naspram rotacionog).

U odnosu na nesimetrične (kakav je i konkretan slučaj konstrukcije čiji je projekat obrađen $u$ predhodnim poglavljima) ovakve zgrade se odlikuju povećanom seizmičkom otpornošću. Za nesimetrične osnove vrlo teško je obezbediti poklapanje centra mase i centra krutosti, što za posledicu ima torziranje zgrade u osnovi. Uticaji izazvani ovim torziranjem mogu biti vrlo značajni i, čak, kod obodnih elemenata, prevazići uticaje translatornog pomeranja.

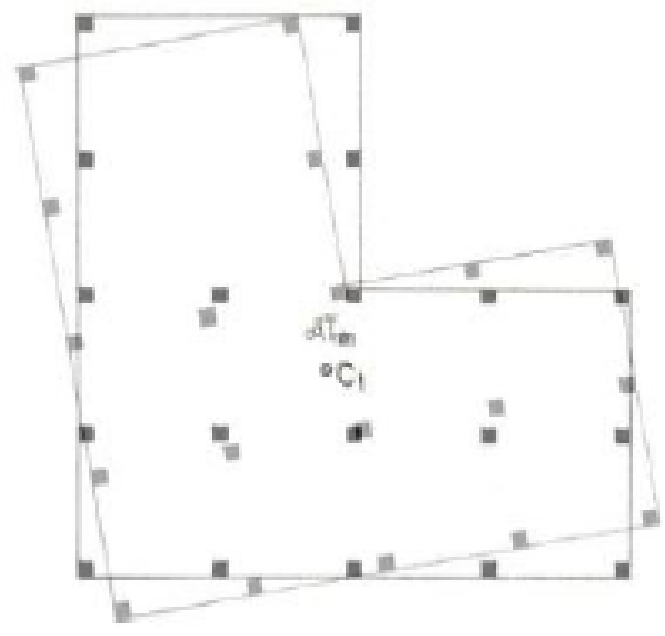

\section{Slika 2. Torziranje zgrade u osnovi}

Prema Evrokodu 8 definisani su kriterijumi regularnosti konstrukcije dopunjujući načelne koji se odnose na simetričnost, uniformnost...

Pri tome konstrukcija i dalje može biti projektovana kao neregularna, ali uz uslov zadovoljenja strožijih uslova (na primer, manje vrednosti faktora ponašanja) $\mathrm{i} / \mathrm{ili}$ nemogućnost korišćenja pojednostavljenih metoda proračuna (prostorni nasuprot ravanskom modelu; modalna analiza nasuprot metodi bočnih sila)

\subsection{Ponašanje konstrukcije u zavisnosti od promene položaja zidova za ukrućenje}

Analizirana su 3 modela konkretne konstrukcije sa različitim rasporedima zidova za ukrućenje. Ideja je da se pokaže koliko promena udaljenost zidova za ukrućenje od centra krutosti utiče na pojavu torzionih efekata.

Analizirana su tri modela sa različitim položajem zidova za ukrućenje u odnosu na centar krutosti. Dobijena zavisnost je prikazana na sledećoj slici. 
Zavisnost udaljenosti zidova za ukrućenje i perioda oscilovanja

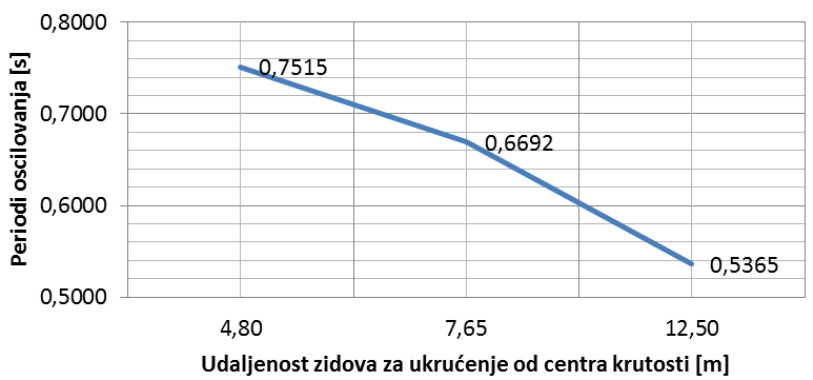

Slika 3. Zavisnost udaljenosti zidova za ukrućenje $i$ perioda oscilovanja

\section{ZAKLJUČAK}

Analizom predhodna tri modela došlo se do zaključka da se po pitanju torzionih efekata, tj. pomeranja i oblika oscilovanja izazvanih torzijom, najbolje ponaša treći model konsrukcije kod kog su zidovi za ukrućenje raspoređeni po obodu konstrukcije. To je potvrda teorije sa početka ovog poglavlja da je po pitanju torzije najbolje postaviti zidove u obodnom delu konstrukcije. Nakon toga analiziran je model 2 gde su zidovi $X$ pravca, a takođe i zidovi Y pravca pomereni ka sredini konstrukcije $\mathrm{i}$ analizirano je ponašanje te konstrukcije u pogledu olika oscilovanja i perioda oscilovanja konstrukcije. Model 1 je model sa 4 zida za ukrućenje u sredini konstrukcije koji su međusobno povezani. Model 1 je po pitanju uticaja torzionih efekata na seizmički odgovor konstrukcije najnepovoljniji iz razloga lošeg rasporeda seizmičkih zidova.

Zaključak teorijskog tela bio bi potvrda teorija koje su postavljene na početku ovog poglavlja. Analizom svih ovih modela, čiji su rezultati grafički prikazani dolazimo do sledećih zaključaka:

- Zidovi orijentisani u X i Y pravcu sprečavaju translatorno pomeranje konstrukcije objekta ali nisu garancija da neće biti torziranja osnove zgrade i njenih nepovoljnih efekata u slučaju seizmičkog opterećenja. Pored postojanja zidova X i Y pravca vrlo je bitan njihov raspored kako bi se sprečilo torziranje zgrade u osnovi.

- Zidovi za ukućenje, tačnije njihov položaj treba biti što udaljeniji od centra krutosti konstrukcije kako bi se suprotstavili što efikasnije torzionom momentu (idealan položaj jeste obodni deo kosntrukcije)
- Zidovi jednog pravca ako su dobro orijentisani mogu da spreče torziranje osnove zgrade

- Sprečavanje neželjenih torzionih efekata usled seizmičkog opterećenja na našu konstrukciju zavisi kako od broja seizmičih zidova tako i od njihovog rasporeda koji je vrlo bitan.

- Čak i manji ekscentriciteti sa nepovoljnim rasporedom seizmičkih zidova mogu da izazovu velike torzione efekte a samim tim veća pomeranja i veće uticaje, naročito u vertikalnim elementima koji se nalaze po obimu kosntrukcije.

\section{LITERATURA}

[1] Evrokod 1: Dejstva na konstrukcije, Beograd, 2009.

[2] Evrokod 2: Proračun betonskih konstrukcija, Beograd, 2009.

[3] Evrokod 8: Proračun seizmički otpornih konstrukcija, Beograd 2009

[4] Dr. Zoran Brujić: "Materijal sa predavanja iz predmeta Betonske konstrukcije", Novi Sad 2015.

[5] Živorad Radosavljević, Dejan Bajić: “Armirani beton 3"- Građevinska knjiga, Beograd 2008.

[6] S. Stefanović: Fundiranje, Naučna knjiga, Beograd 1989.

[7] M. Čaušević: Dinamika konstrukcija, Tehnička knjiga, Zagreb 2010.

\section{Kratka biografija:}

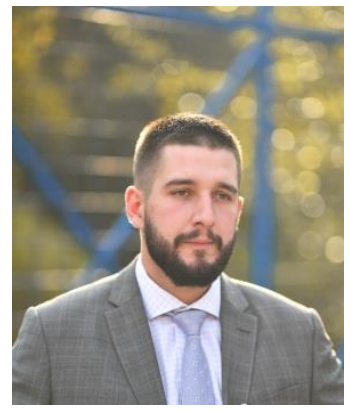

Igor Lazarević rođen je u Užicu 1993. god. Master rad na Fakultetu tehničkih nauka iz oblasti Građevinarstva - Seizmička analiza konstrukcije odbranio je 2019.god. 